\title{
Highly Sensitive Ratiometric Chemosensor and Biomarker for Cyanide lons in the Aqueous Medium
}

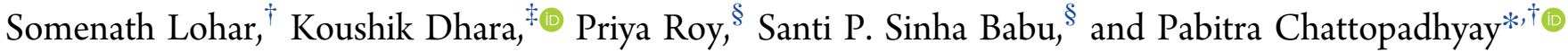 \\ ${ }^{\dagger}$ Department of Chemistry, The University of Burdwan, Burdwan 713104, West Bengal, India \\ ${ }^{\ddagger}$ Department of Chemistry, Sambhu Nath College, Labpur, Birbhum 731303, West Bengal, India \\ ${ }^{\S}$ Parasitology Laboratory, Department of Zoology, Visva-Bharati University, Santiniketan, 731235, India
}

\section{Supporting Information}

\begin{abstract}
A newly designed cyanide-selective chemosensor based on chromone containing benzothiazole groups [3-(2,3-dihydro-benzothiazol-2-yl)-chromen-4-one (DBTC)] was synthesized and structurally characterized by physicochemical, spectroscopic, and single-crystal X-ray diffraction analyses. The compound DBTC can detect cyanide anions based on nucleophilic addition as low as $5.76 \mathrm{nM}$ in dimethyl sulfoxide- $N$-(2-hydroxyethyl)piperazine- $N^{\prime}$-ethanesulfonic acid buffer $(20 \mathrm{mM}, \mathrm{pH} 7.4)(\mathrm{v} / \mathrm{v}=1: 3)$. The binding mode between receptor DBTC and cyanide nucleophile has also been demonstrated by experimental studies using various spectroscopic tools and theoretical studies, and the exper-

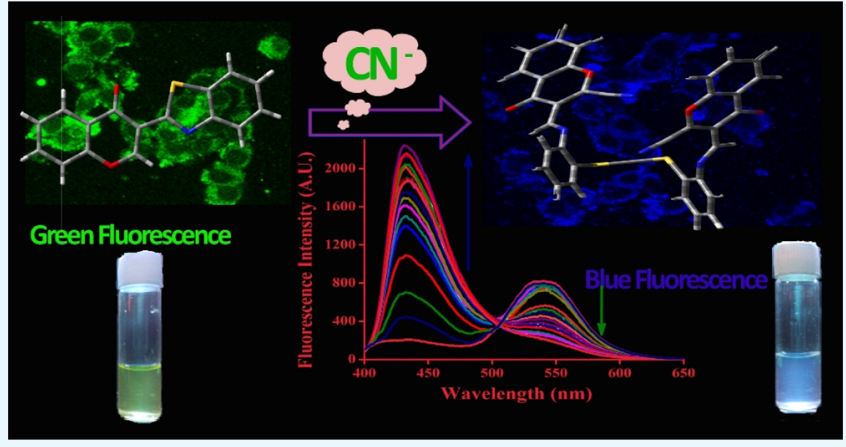
imental work has also been verified by characterizing one supporting compound of similar probable structure of the final product formed between DBTC and cyanide ion (DBTC-CN compound) by single-crystal X-ray analysis for detailed structural analyses. In theoretical study, density functional theory procedures have been used to calculate the molecular structure and the calculation of the Fukui function for evaluation of the electrophilic properties of each individual acceptor atom. Furthermore, the efficacy of the probe (DBTC) to detect the distribution of $\mathrm{CN}^{-}$ions in living cells has been checked by acquiring the fluorescence image using a confocal microscope. Notably, the paper strips with DBTC were prepared, and these could serve as efficient and suitable $\mathrm{CN}^{-}$test kits successfully.
\end{abstract}

\section{INTRODUCTION}

The detection and recognition of anionic analytes have become a field of a huge awareness in recent years. ${ }^{1-8}$ Among a wide range of anions, cyanide $\left(\mathrm{CN}^{-}\right)$ion has been paid considerable attention because of its acutely toxicity; existence in many natural sources such as apple seeds, cassava, and peach kernel and production by certain microbes such as fungus and bacteria. ${ }^{9-11}$ In human body, this cyanide ion binds with iron within the protein strongly, which inhibit the enzyme cytochrome $c$ oxidase process and hinder the electron transport; and in turn, this results in vomiting and convulsion and then loss of consciousness and eventual death. ${ }^{12,13}$ However, in numerous industrial processes, cyanide as an important chemical anion plays an imperative role in many areas, for example, electroplating and case-hardening of metals, gold mining and extraction, and synthesis of resins, fibers, pharmaceuticals, pesticides, and intermediates, and so on. ${ }^{14-18}$ As a result, different international, national, and local regulations and guidelines regularize the level of cyanide in air, water, and other media. ${ }^{19}$ The maximum contaminant level for cyanide set by the US EPA in drinking water is $200 \mathrm{~g} \mathrm{~L}^{-1}$ where as it is $70 \mathrm{~g} \mathrm{~L}^{-1}$ by the World Health Organization limit in drinking water. ${ }^{20,21}$ In spite of the acute toxicity, lower limits of cyanide ion is required for ecosystems and it is as much as 4 and $2 \mathrm{~g} \mathrm{~L} \mathrm{~L}^{-1}$ set by the Australian and New Zealand Environmental and Conservation Council, respectively, to protect the $99 \%$ of the species in the freshwater and marine water. $^{22}$ Thus, it has been an utmost crucial task to exploit effective ways for monitoring the presence of cyanide anion, and ultimately, the development of highly selective chemosensor for cyanide ion has become the cynosure to the chemists.

Conventional techniques such as potentiometry, ${ }^{23}$ electrochemical, ${ }^{24}$ polarography, ${ }^{25}$ simple titrations, ${ }^{26}$ and flow injection amperometric ${ }^{27}$ are time-consuming. Therefore, there is an increasing demand of development of more efficient and sensitive methods to measure cyanide ions directly at the microgram/liter level in different matrices. In this context, fluorescent chemosensors for cyanide ions are significantly attractive because of low cost and present numerous advantages, including high sensitivity and easy operation. $^{28,29}$

$\mathrm{CN}^{-}$selective receptors based on the mechanism of nucleophilic addition reactions, ${ }^{30-34}$ hydrogen-bonding inter-

\footnotetext{
Received: May 17, 2018

Accepted: July 20, 2018

Published: August 30, 2018
} 
actions, ${ }^{35,36}$ coordination, ${ }^{37}$ sol-gel technique, ${ }^{38}$ ion recognition, ${ }^{39-44}$ and metal-cyanide affinity (displacement approach $)^{45-47}$ have been reported. In this regard, various organic compounds have been employed as the fluorophore moiety was exploited as sensors for cyanide, hitherto, naphthalene, ${ }^{48,49}$ naphthalimide, ${ }^{50}$ coumarin, ${ }^{51}$ indole, ${ }^{52}$ BODIPY, ${ }^{53}$ phenothiazine, ${ }^{54}$ phenazine ${ }^{55}$ but chromone-based selective $\mathrm{CN}^{-}$anion chemosensors are still unexplored.

However, there are a very few "turn-on" and "ratiometric" cyanide sensing probes in the literature. ${ }^{5,57}$ As the molecular systems of the enhanced/ratiometric fluorescence signal response with the addition of the target analyte are generally superior in response to those systems of the "turn-off" or quenching fluorescence signals, the design of cyanide-selective chemosensors based on off-on/ratiometric signaling pathway is a very meaningful and demanding task. Herein, we have designed, synthesized, and structurally characterized a new chromone-based ratiometric chemosensor probe $[3-(2,3-$ dihydro-benzothiazol-2-yl)-chromen-4-one (DBTC)] which selectively senses $\mathrm{CN}^{-}$ions as low as $5.76 \mathrm{nM}$ in dimethyl sulfoxide- $\mathrm{N}$-(2-hydroxyethyl)piperazine- $\mathrm{N}^{\prime}$-ethanesulfonic acid (DMSO-HEPES) buffer (20 mM, pH 7.4) (v/v = 1:3). The probe (DBTC) is competent of detecting and sensing the distribution of $\mathrm{CN}^{-}$ions in living cells, which was confirmed by a confocal microscope. Moreover, the DBTC-based paper strips can also be used as $\mathrm{CN}^{-}$ion test kits as these strips remarkably senses $\mathrm{CN}^{-}$ions.

\section{RESULTS AND DISCUSSION}

2.1. Synthesis of the DBTC. The organic moiety DBTC was synthesized by condensation of 3-formylchromone with 2aminothiophenol (1:1 mole ratio) in anhydrous ethanol (Scheme 1). After cooling, the yellow-colored precipitate was

Scheme 1. Synthetic Procedure of the Probe DBTC and DBTC-CN Complex

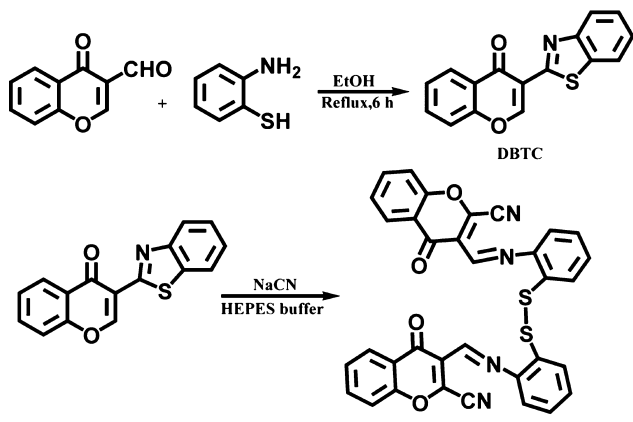

DBTC-CN complex

obtained, washed with hot ethanol two times, and then dried giving a yellow-colored shiny crystalline compound. Its chemical structure was well characterized by electrospray ionization (ESI) mass spectrometry, ${ }^{1} \mathrm{H} \mathrm{NMR},{ }^{13} \mathrm{C} \mathrm{NMR}$, and infrared (IR) spectra (Figures S1-S4, Supporting Information) and elemental analysis. Finally, the confirmation of the structure of the organic moiety (DBTC) was established by single-crystal X-ray crystallographic analysis (Figure 1).

Light yellow block-shaped crystals of DBTC suitable for single-crystal X-ray diffraction analysis were obtained after 15 days of slow evaporation of an ethanol solution. DBTC crystallized into the monoclinic space group $P 2_{1} / n$ with $Z=4$ and cell volume 1232.19 (Table S1). The organic moiety of

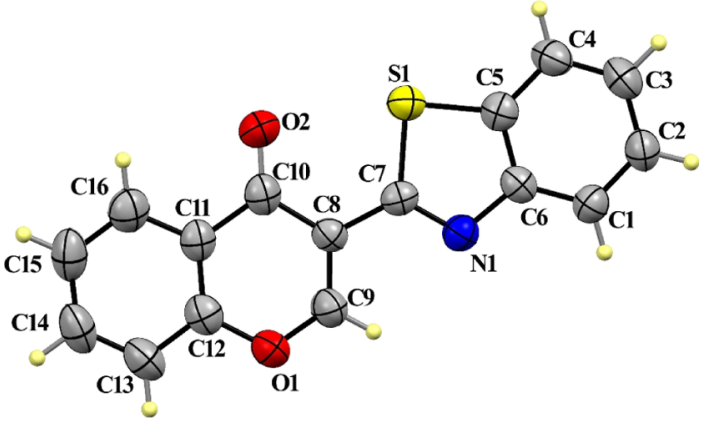

Figure 1. Structural representation and atom numbering scheme of DBTC.

DBTC has excellent planarity between chromone and benzothiazole ring with the dihedral angle $3.65^{\circ}$, which is beneficial to green fluorescence properties. A schematic view of the DBTC motif is shown in Figure 1; the selected bond lengths and angles are tabulated in Tables S1 and S2 in the Supporting Information.

2.2. Synthesis of the DBTC-CN Complex. The ethanolic solution of DBTC and aqueous solution of $\mathrm{NaCN}$ is mixed in equimolar ratio, and the resulting mixture was stirred for $2 \mathrm{~h}$ (Scheme 1). The clear resulting solution was filtered, and after three weeks, a reddish black color precipitate was obtained. The DBTC-CN complex was characterized by ESI mass and ${ }^{1} \mathrm{H}$ NMR, ${ }^{13} \mathrm{C} \mathrm{NMR}$, and IR spectra (Figures S5-S8).

The emission spectra of DBTC studied in different solvents of varying polarity (Figure 2) show the largely red-shifted

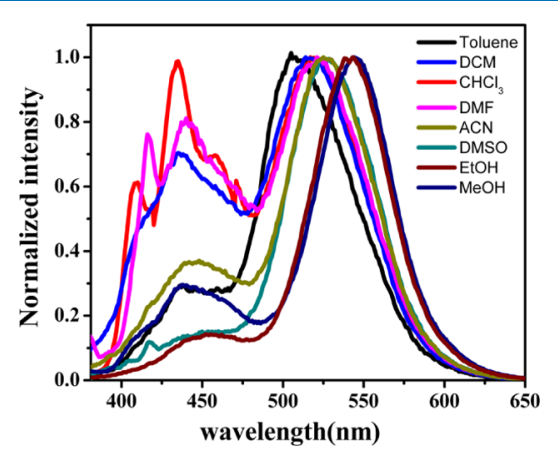

Figure 2. Emission spectra of DBTC $\left(\lambda_{\text {ex }}=370 \mathrm{~nm}\right)$ in toluene, dichloromethane, $\mathrm{CHCl}_{3}$, dimethylformamide, $\mathrm{CH}_{3} \mathrm{CN}$, DMSO, $\mathrm{EtOH}$, and $\mathrm{MeOH}$ solvents.

fluorescence spectra of DBTC with the increase of the solvent polarity. This trend of the characteristic peaks is in support of the ICT pathway as in polar solvents $\left(\mathrm{CH}_{3} \mathrm{CN}, \mathrm{DMSO}, \mathrm{EtOH}\right.$, and $\mathrm{MeOH})$ the charge-transfer emission is very significant.

2.3. UV-Visible Studies. The absorption spectrophotometric titration in HEPES $(20 \mathrm{mM})$ buffer at $\mathrm{pH} 7.4$ was carried out at $37{ }^{\circ} \mathrm{C}$ to understand the mode of interaction of DBTC with $\mathrm{CN}^{-}$ions, and it is depicted in Figure 3 which demonstrates the UV-vis titration curve of DBTC with added $\mathrm{CN}^{-}$ion.

With the stepwise increase of the concentration of added $\mathrm{CN}^{-}$ions, the absorption intensity of DBTC at $350 \mathrm{~nm}$ gradually decreases with the appearance of new peaks of weak absorption intensity at 305 and $460 \mathrm{~nm}$. The phenomenon of 


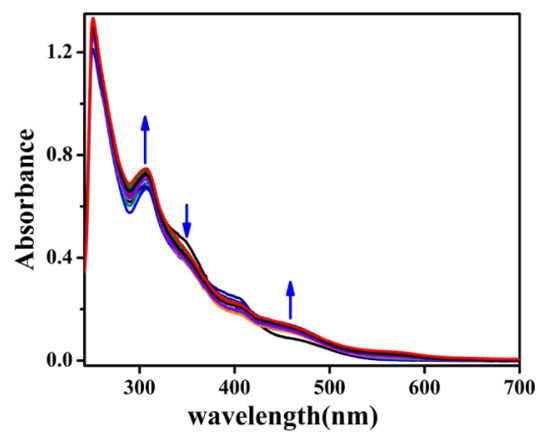

Figure 3. Absorption spectra of DBTC $(10 \mu \mathrm{M})$ in DMSO-HEPES buffer $(20 \mathrm{mM}, \mathrm{pH} 7.4)(\mathrm{v} / \mathrm{v}=1: 3)$ upon the titration with $\mathrm{CN}^{-}$ion solution.

increase of new peaks with the increase of cyanide ions is due to the interaction of the probe (DBTC) with $\mathrm{CN}^{-}$ion.

2.4. $\mathrm{pH}$ Studies. The role of $\mathrm{CN}^{-}$ions in biological systems is significantly noteworthy. Therefore, it is imperative of having an efficient sensing probe applicable for detection of cyanide ions over a wide range of $\mathrm{pH}$. To verify the $\mathrm{pH}$ effect, the emission spectra (at $\lambda_{\mathrm{em}}=430 \mathrm{~nm}$ ) of the probe (DBTC) $(10 \mu \mathrm{M})$ without and with $\mathrm{CN}^{-}$(1 equiv) were recorded over a wide range of $\mathrm{pH} 4-12$ (Figure S9). This study clearly indicates that the detection of $\mathrm{CN}^{-}$ions is possible at the biological $\mathrm{pH} 7.4$ in DMSO-HEPES buffered solution (1:3 v/ v).

2.5. Fluorescence Studies. The fluorescence profiles of DBTC and their potential $\mathrm{CN}^{-}$reaction products are even more distinct than their corresponding UV-vis spectra. The fluorescence intensity dramatically enhances at $\lambda_{\mathrm{em}}=430 \mathrm{~nm}$ with the progress of time (Figure S10). A considerable effect on the emission profile of DBTC was observed because of the incremental addition of $\mathrm{CN}^{-}$ions. Here, a huge blue shift of the fluorescence maximum from 540 to $430 \mathrm{~nm}$ through an isoemissive point at $505 \mathrm{~nm}$ was recorded, and it is of about $110 \mathrm{~nm}$ (Figure 4). It is noteworthy to mention that the

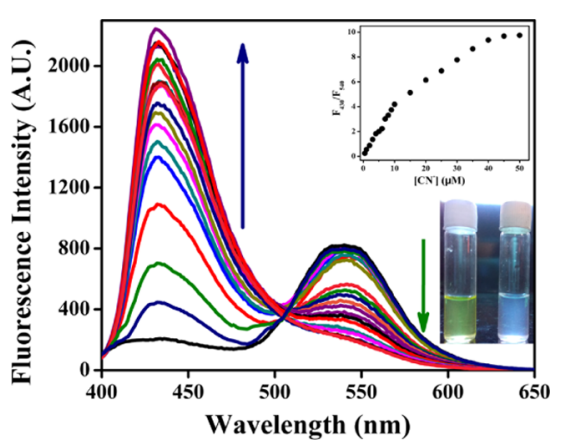

Figure 4. Fluorescence spectra of DBTC $(10 \mu \mathrm{M})$ upon the addition of $0-10$ equiv $\mathrm{CN}^{-}$anion in DMSO-HEPES buffer solution (20 $\mathrm{mM}, \mathrm{pH} 7.4)(\mathrm{v} / \mathrm{v}=1: 3)$.

fluorescence intensity at $540 \mathrm{~nm}$ was gradually decreased with concomitant increase of the newly appeared fluorescence maxima at $430 \mathrm{~nm}$. Interestingly, a plateau was obtained after 10 equiv addition of $\mathrm{CN}^{-}$ions. This emission profile clearly suggests the formation of a well-defined DBTC-CN compound.

In addition, from this study, it is observed that the ratio of the emission intensities at 430 and $540 \mathrm{~nm}\left(I_{430} / I_{540}\right)$ increased to 9.9 from 0.24 ( $\sim 41$-fold enhancement) upon the gradual addition of $\mathrm{CN}^{-}$ions (inset of Figure 4). This result significantly designates the probe (DBTC) as a ratiometric fluorescent chemosensor for $\mathrm{CN}^{-}$ions. This spectroscopic change has been supported by the visual color change of the DBTC solution of DBTC from green to blue because of the addition of 10 equiv $\mathrm{CN}^{-}$ions upon excitation by a hand held UV lamp of $370 \mathrm{~nm}$ (Figure 4, inset).

These fluorescence spectral data were used to draw the Job's plot (Figure S11) curves to calculate the stoichiometry of the interaction of the DBTC receptors with cyanide ions. This curve with the maxima at $\sim 0.5$ mole fraction dictates the formation of 1:1 (receptor/cyanide ion) ensemble/compound. From the fluorescence titration data, the binding constant toward the formation of the DBTC-CN compound was calculated to be $4.25 \times 10^{5} \mathrm{M}^{-1}$ using the modified BenesiHildebrand equation ${ }^{66}$ corresponding to $1: 1$ stoichiometry.

$$
1 /\left(F_{\mathrm{x}}-F_{0}\right)=1 /\left(F_{\max }-F_{0}\right)+(1 / K[C])\left(1 /\left(F_{\max }-F_{0}\right)\right.
$$

where $F_{0}, F_{x}$ and $F_{\infty}$ are the emission intensities of DBTC in the absence of $\mathrm{CN}^{-}$ions, at an intermediate $\mathrm{CN}^{-}$ion concentration, and at a concentration of complete interaction, respectively, and where $K$ is the binding constant and $[C]$ is the $\mathrm{CN}^{-}$ion concentration. From the intercept/slope of the plot of $\left(F_{\infty}-F_{0}\right) /\left(F_{x}-F_{0}\right)$ against $[C]^{-1}$ (Figure 5), the $K$ value was determined to be $4.25 \times 10^{5} \mathrm{M}^{-1}$ which clearly indicates that DBTC has a significantly strong binding affinity toward the $\mathrm{CN}^{-}$ions.

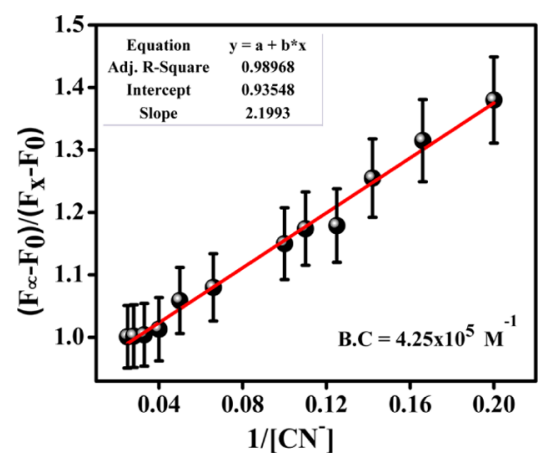

Figure 5. Plot of $\left(F_{\infty}-F_{0}\right) /\left(F_{x}-F_{0}\right)$ against $1 /[\mathrm{CN}]^{-1}$ : Binding constant $(K)$ of $4.25 \times 10^{5} \mathrm{M}^{-1}$ for $\mathrm{CN}^{-}$ions with DBTC.

To find the limit of detection of $\mathrm{CN}^{-}$by the probe, that is, how lower amount (minimum concentration) of $\mathrm{CN}^{-}$anion can be estimated by the probe (DBTC), from the fluorescence titration study, it was found that minimum $5.76 \mathrm{nM} \mathrm{CN}^{-}$ anion can develop the fluorescence intensity ratio $\left(I_{430} / I_{540}\right)$ of DBTC (Figure 6).

Therefore, the detection limit (LOD) of DBTC for $\mathrm{CN}^{-}$ ions was calculated to be $5.76 \mathrm{nM}$ by the use of the equation $3 \sigma / S$ (where $S=$ gradient of the calibration curve and $\sigma$ is the standard deviation at zero level). ${ }^{67}$ This LOD value $(5.76 \mathrm{nM})$ of DBTC for $\mathrm{CN}^{-}$ions calculated from this method is significantly lower than that of MCL.

To evaluate the sensing selectivity of DBTC, fluorescence changes toward $\mathrm{CN}^{-}$, various anions were verified in replicate experiments under the same conditions. Among various competing anions, only cyanide ions incredible response of the fluorescence intensity ratio $\left(I_{430} / I_{540}\right)$, whereas the other anions such as $\mathrm{SCN}^{-}, \mathrm{F}^{-}, \mathrm{Cl}^{-}, \mathrm{Br}^{-}, \mathrm{I}^{-}, \mathrm{ClO}^{-}, \mathrm{ClO}_{4}^{-}, \mathrm{N}_{3}^{-}$, $\mathrm{NO}_{2}{ }^{-}, \mathrm{NO}_{3}{ }^{-}, \mathrm{H}_{2} \mathrm{PO}_{4}^{-}, \mathrm{H}_{2} \mathrm{AsO}_{4}{ }^{-}, \mathrm{HCO}_{3}{ }^{-}, \mathrm{HS}^{-}, \mathrm{S}^{2-}, \mathrm{HSO}_{3}^{-}$, 


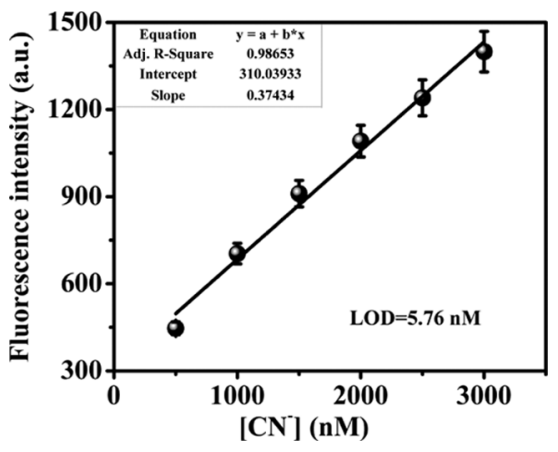

Figure 6. Plot for the estimation of LOD for cyanide ions in the DMSO-HEPES buffer $(20 \mathrm{mM})$ solution $(\mathrm{v} / \mathrm{v}=1: 3)$ at $\mathrm{pH} 7.4$.

$\mathrm{HSO}_{4}{ }^{-}$, and $\mathrm{AcO}^{-}$did not bring any significant change in the emission intensity ratio $\left(I_{430} / I_{540}\right)$ plot (viz., Figure S12). This is reasonable considering the stronger nucleophilicity of cyanide compared with other anions. In addition, to verify the interference, we evaluate the fluorescence response of DBTC with $\mathrm{CN}^{-}$in the presence of other competitive anions and cations (viz., Figures S13 and S14), which clearly showed that the signal response of DBTC induced by $\mathrm{CN}^{-}$was not hampered at any extent by the presence of other different anions and cations.

2.6. Density Functional Theoretical Studies. To investigate the mechanism of the ratiometric response of probe DBTC to cyanide ion, density functional theory (DFT) calculations were carried out for the probe DBTC and DBTC-CN compound with the B3LYP/6-31G(d) method. The optimized geometries of DBTC and DBTC-CN compound are shown in Figure 7. DBTC was almost planar,
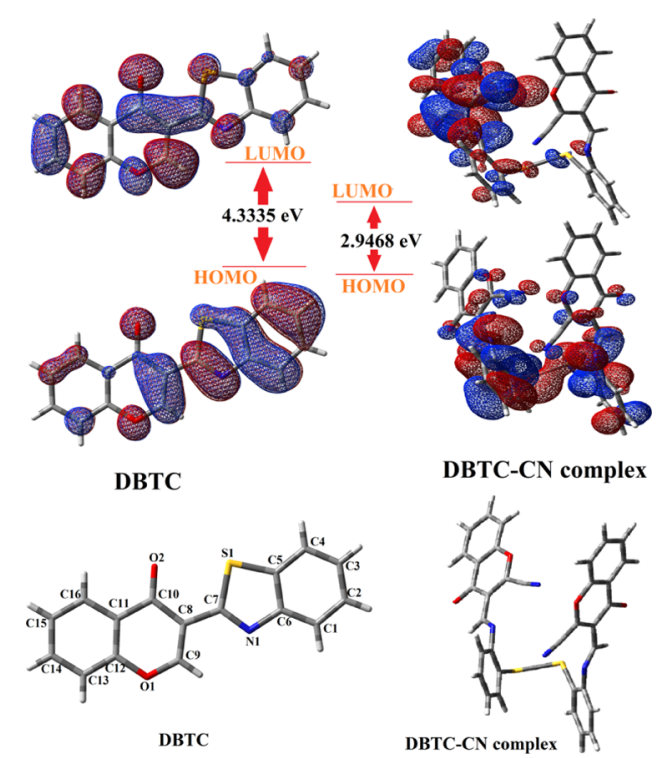

Figure 7. HOMO-LUMO energy calculation and optimized structure of DBTC and DBTC-CN compound.

with a dihedral angle of $3.65^{\circ}$ between the chromone and benzothiazole moiety which make this two groups in good conjugation, whereas the DBTC-CN compound reveals a tilted conformation with dihedral angle $19.80^{\circ}$, indicating a hampered conjugation. Therefore, the ICT process between chromone and benzothiazole group could proceed efficiently in probe DBTC but be inhibited in the DBTC-CN compound.
This reduced ICT character of the probe is due to the disruption of the $\pi$-conjugation in the DBTC-CN compound, and in turn, the significant blue shift in the emission spectrum is occurred. It is also well supported by considering the comparison of HOMO-LUMO energy band gaps of DBTCCN compound which is lower than DBTC.

The time-dependent DFT (TDDFT) calculations show two important peaks in the 252.44 and $331.65 \mathrm{~nm} \mathrm{UV} \mathrm{spectra} \mathrm{of}$ DBTC in water. The band around $331.65 \mathrm{~nm}$ is governed by the HOMO $\rightarrow$ LUMO excitations, and the band around $252.44 \mathrm{~nm}$ is essentially due to HOMO $-8 \rightarrow \mathrm{LUMO}+1$; $\mathrm{HOMO}-7 \rightarrow$ LUMO +1 ; HOMO $-7 \rightarrow$ LUMO +4 ; $\mathrm{HOMO}-7 \rightarrow \mathrm{LUMO}+6$; $\mathrm{HOMO}-4 \rightarrow \mathrm{LUMO}+1$; $\mathrm{HOMO}-4 \rightarrow \mathrm{LUMO}+4$; and HOMO $-4 \rightarrow \mathrm{LUMO}+6$ transitions (Figure S15). In the case of DBTC-CN compound, the calculated band around $467.87 \mathrm{~nm}$ is attributable to the HOMO $-2 \rightarrow$ LUMO; HOMO $-2 \rightarrow$ $\mathrm{LUMO}+2$; HOMO - $1 \rightarrow$ LUMO; HOMO - $1 \rightarrow$ LUMO $+1 ; \mathrm{HOMO} \rightarrow$ LUMO; and HOMO $\rightarrow$ LUMO + 2 transitions (Figure S16). All of the detailed vertical excitation energies, oscillator strengths, and salient transitions are tabulated in Tables S4 and S5.

To recognize the most suitable atoms for nucleophilic attack, ${ }^{68}$ the condensed Fukui function values $f_{k}{ }^{+}$may be used. These values were calculated to examine the electrophilicity properties of the acceptor atoms of the probe DBTC. Selected $f_{k}{ }^{+}$values are given in Table 1 , considering the atom numbering scheme, viz., Figure 1.

Table 1. Selected $f_{k}{ }^{+}$Values Calculated for DBTC

$\begin{array}{ccccc}\text { atom } & \text { C7 } & \text { C8 } & \text { C9 } & \text { C10 } \\ f_{k}^{+} & 0.0299 & -0.0169 & 0.1244 & 0.0524\end{array}$

On the basis of the calculated values of the Fukui functions (viz., Table 1), it may be concluded that the C9 acceptor atoms may be predictable to be much stronger acceptor atoms than the $\mathrm{C} 7, \mathrm{C} 8$, and $\mathrm{C} 9$ atoms. Hence, $\mathrm{CN}^{-}$anion (nucleophile) can attack the $\mathrm{C} 9$ carbon atom which is the most electrophilic center in the DBTC probe. Unfortunately, we failed to get the single crystals of the product, the DBTCCN compound diffractable for single-crystal X-ray diffraction analysis although the probable structure of the DBTC-CN compound has been established by various spectroscopic analyses (ESI mass: Figure S5, ${ }^{1} \mathrm{H}$ NMR: Figure S6, ${ }^{13} \mathrm{C}$ NMR: Figure S7 and IR: Figure S8). In addition, the analogue compound (DBTC-OCH 3 (1)) having the methoxy group (similar nucleophile as cyanide) has been isolated from the same chemical environment using methanol to establish the fact of the formation of the DBTC-CN compound in the ethanol-cyanide mixture. Fortunately, the detailed structure analysis of the compound, DBTC-OCH $\mathbf{3}(\mathbf{1})$, has been carried out by single-crystal X-ray diffraction analysis (Figure 8). This structural analysis (Table S3) dictates the possibility of nucleophilic addition of cyanide ion to the $\mathrm{C} 9$ carbon atom of the chromone moiety of DBTC to produce the DBTC-CN compound.

On the basis of all spectroscopic and theoretical observations, the plausible sensing pathway has been depicted in Scheme 2.

2.7. Cell Imaging Studies. To validate the efficacy of this probe having significant fluorescence color change in solution, some test strips were prepared by immersing filter papers in 


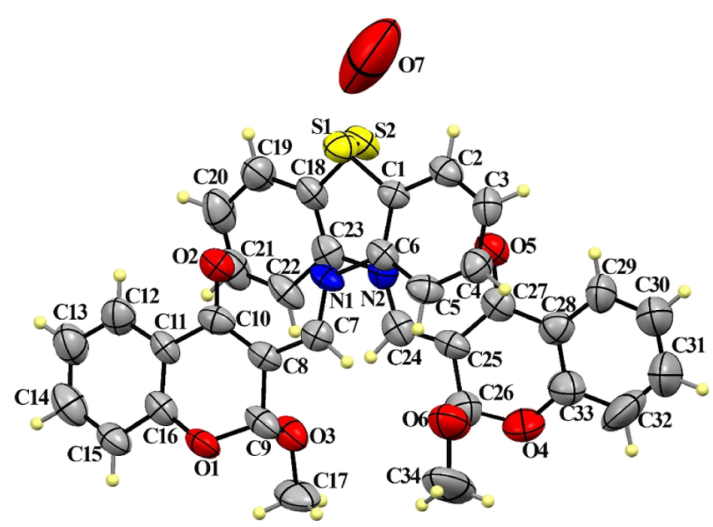

Figure 8. Crystal structures of the compound $\mathrm{DBTC}^{-} \mathrm{OCH}_{3}(\mathbf{1})$.

Scheme 2. Proposed DBTC-CN Formation from Reaction of Receptor DBTC and Cyanide

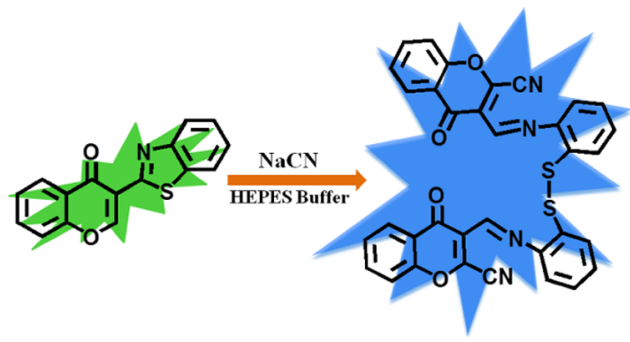

the DMSO $/ \mathrm{H}_{2} \mathrm{O}$ solution of DBTC $(1.0 \mathrm{mM})$ and then dried in air. The DBTC-based test strips were dipped in several aqueous media of $\mathrm{CN}^{-}$ions of different concentrations, and the fluorescence color change from green to blue was observed with gradually increasing concentration of cyanide ions (Figure 9). Therefore, this interesting experiment reflects that the DBTC-based test strips can suitably detect $\mathrm{CN}^{-}$in solutions without any other tools.

To examine the effectiveness of the probe for $\mathrm{CN}^{-}$ion detection in biological systems, it was performed using human breast adenocarcinoma cell line MDA. In these experiments, both the DBTC and $\mathrm{CN}^{-}$ions were allowed to uptake by the cells of interest and the images of the cells were recorded by the fluorescence microscopy, following excitation at $\sim 370 \mathrm{~nm}$. Incubation of DBTC alone showed green fluorescence uptake even after 90 min. Uptake into MDA cells was boosted upon using cyanide anion showed blue fluorescence (Figure 10).

To verify the compatibility of uses of this probe in the living cells, the cytotoxic effect of the probe (DBTC) was tested

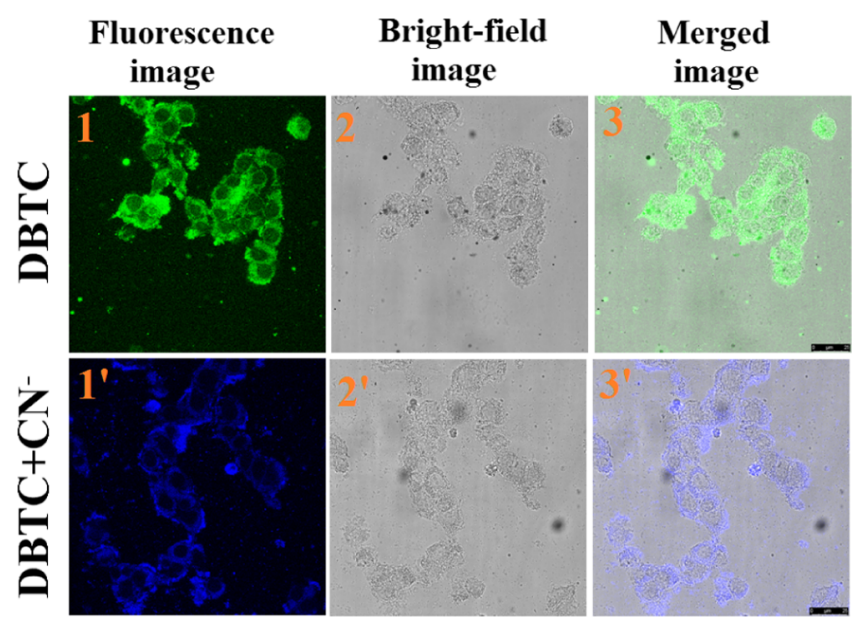

Figure 10. Confocal fluorescence microscopy images of MDA cells with DBTC only and DBTC plus cyanide ions at $37^{\circ} \mathrm{C}$.

against breast adenocarcinoma cells MDA using a regular method, the MTT assay. ${ }^{69}$ The probe (DBTC) showed about $80 \%$ cell survivability at their working concentration $[100 \mu \mathrm{g} /$ $\mathrm{mL}$ for probe (DBTC)] after 1 and $24 \mathrm{~h}$ of incubation both the cases toward cancer cells. Therefore, the probe (DBTC) at a concentration of $100 \mu \mathrm{g} / \mathrm{mL}$ can be used safely for the purpose of fluorescence imaging of cancer cells (Figure S17).

\section{CONCLUSIONS}

Herein, we have developed an easy to synthesize and structurally characterized potential ratiometric probe (DBTC) which detects $\mathrm{CN}^{-}$ions fluorimetrically as low as $5.76 \mathrm{nM}$ anions based on nucleophilic addition in the DMSOHEPES buffer $(20 \mathrm{mM}, \mathrm{pH} 7.4)(\mathrm{v} / \mathrm{v}=1: 3)$. Interestingly, the probe (DBTC) shows the incredible response for cyanide ions specifically over other common anions. This significantly enhanced fluorescence intensity is due to the nucleophilic addition of the nucleophile cyanide ion to the $\mathrm{C} 9$ carbon atom of the chromone moiety to form DBTC-CN compound, and it is well supported by the isolation of $\mathbf{D B T C}^{-\mathbf{O C H}_{3}}$ (1), an analogue of DBTC-CN compound. The possibility of DBTC-CN compound is confirmed by the detailed spectroscopic techniques and theoretical studies. The structural analysis of DBTC-OCH the feasibility of nucleophilic addition of potential nucleophile (cyanide ion is more potential nucleophile than methoxide ion) to the C9 carbon atom of the chromone moiety. This noncytotoxic probe (DBTC) is competent of acquiring the

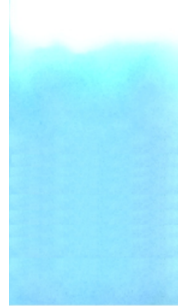

$\mathbf{L}$

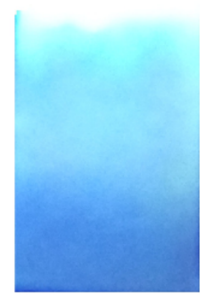

$\mathbf{L}+\mathbf{0 . 5}$ eq

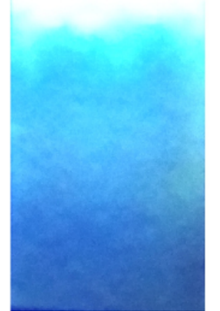

$\mathbf{L}+\mathbf{1}$ eq

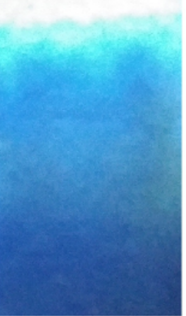

$\mathbf{L}+1.5 \mathrm{eq}$

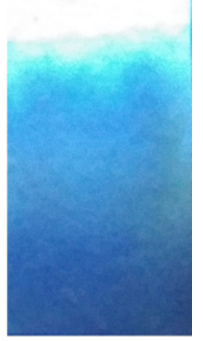

$\mathbf{L}+2$ eq

Figure 9. Photographs of only DBTC $(1.0 \mathrm{mM})$ and after immersion into water solutions with increasing $\mathrm{CN}^{-}$anion on test strips at room temperature and irradiation under UV light at $370 \mathrm{~nm}$. 
images of the distribution of cyanide ions in living bodies, and it was confirmed by the confocal microscopic imaging. Again, it is also noteworthy that the DBTC-based paper strips can also be used as $\mathrm{CN}^{-}$ion test kits as these strips sense $\mathrm{CN}^{-}$ions significantly. This developed method of cyanide ion detection in the aqueous medium is superior to the earlier reports (viz., Table S6) in terms of the detection limit and the solvent medium. This ratiometric probe (DBTC) can sense as low as $5.76 \mathrm{nM} \mathrm{CN}^{-}$ions fluorimetrically, which is also lower than the lowest value ( $30 \mathrm{nM} \mathrm{CN}^{-}$ions) of the reported literature tabulated in the comparative table (Table S6).

\section{EXPERIMENTAL SECTION}

4.1. Materials and Methods. Standard procedures have been performed to purify and dry the solvents used for spectroscopic studies, but all other chemicals and reagents purchased from Sigma-Aldrich were used without any purification. Solutions of the anions were prepared from their sodium salts of cyanide, thiocyanate, arsenate, azide, nitrite, nitrate, bicarbonate, hydrogen sulfide, hydrogen sulfite, hydrogen sulfate, hypochlorite, chlorate, and tetrabutylammonium salts of halides $\left(\mathrm{F}^{-}, \mathrm{Cl}^{-}, \mathrm{Br}^{-}\right.$, and $\left.\mathrm{I}^{-}\right)$, acetate, and dihydrogen phosphate. In HEPES $(20 \mathrm{mM})$ buffered water at $\mathrm{pH} 7.4$, all of the experiments for titration were carried out at $25{ }^{\circ} \mathrm{C}$.

Mass spectra were recorded on a micrOTOF-Q mass spectrometer and XeVOG2QTof HRMS spectrometer in methanol. H NMR was carried out using the Bruker AVANCE DPX $500 \mathrm{MHz}$ spectrometer. Elemental analyses (C, H, and N) were carried out with a PerkinElmer CHN analyzer 2400. A Systronics $\mathrm{pH}$ meter (model 335) was used for the $\mathrm{pH}$ measurements. Fourier transform IR (FTIR) spectra were done as $\mathrm{KBr}$ pellets using a Prestige-21 FTIR spectrophotometers.

A yellow-colored crystal of DBTC was mounted on a glass tip, and data were collected in a Bruker's APEX-II CCD diffractometer using $\operatorname{MoK}_{\alpha}(\lambda=0.71069)$; necessary corrections were applied using SADABS from Bruker. ${ }^{58}$ Fourier full-matrix least-squares refinement methods based on $F^{2}$, using SHELX-97 was used to refine all of the nonhydrogen atoms anisotropically in order to solve the structure. ${ }^{59}$ WinGX package was also utilized for all of the calculations. ${ }^{60,61}$ As per the deposition of the cif files with the Cambridge Crystallographic Data Centre, the codes were allocated as CCDC-1835425 and 1835426 of DBTC and 1, respectively.

4.2. Theoretical Calculation. The DFT method at the B3LYP level ${ }^{62}$ with Gaussian-09 software over a Red Hat Linux IBM cluster ${ }^{63}$ was used for full geometry optimizations of DBTC and their corresponding complexes. The 6-31G(d) basis set was employed for all of the elements. Computation of vertical electronic excitations based on B3LYP optimized geometry was performed using the time-dependent DFT (TDDFT $)^{64}$ formalism in water with the conductor-like polarizable continuum model ${ }^{65}$ to calculate the fractional contributions of various groups to each molecular orbital.

4.3. General Procedure for Fluorescence and Absorption Study. Path length of the cells used for absorption and emission studies was $1 \mathrm{~cm}$. The fluorescence properties of the sensor were investigated in DMSO-HEPES buffer solution $(20 \mathrm{mM}, \mathrm{pH} 7.4)(\mathrm{v} / \mathrm{v}=1: 3)$. Fluorescence measurements were performed using $5 \times 5 \mathrm{~nm}$ slit width. All of the fluorescence and absorbance spectra were taken after $30 \mathrm{~min}$ of mixing of $\mathrm{CN}^{-}$and DBTC.

4.3.1. Biological Methods. 4.3.1.1. Cell Culture and Platting. Human breast adenocarcinoma cell line MDA was maintained in Dulbecco's modified Eagle's medium supplemented with $10 \%$ fetal bovine serum and $1 \%$ penicillinstreptomycin antibiotic solution in a humidified $\mathrm{CO}_{2}$ incubator $\left(5 \% \mathrm{CO}_{2}\right)$. The cells were detached from a culture flask using trypsin-EDTA (ethylenediaminetetraacetic acid) solution and washed in the growth medium. After final wash, cells were plated into 96-well microtiter plates $\left(4 \times 10^{3}\right.$ cells per well $)$ for the purpose of MTT assay and permitted $24 \mathrm{~h}$ to adhere. For the purpose of imaging, cells were seeded on $14 \mathrm{~mm}$ glass cover slips into a 6-well microtiter plate and allowed $24 \mathrm{~h}$ for complete adherence.

4.3.1.2. Imaging. Cells growing on glass cover slips were incubated for $1.5 \mathrm{~h}$ with $100 \mu \mathrm{g} / \mathrm{mL}$ aqueous solution of DBTC in the presence and absence of cyanide ion solution (20 $\mu \mathrm{L})$, containing $1 \% \mathrm{DMSO}(\mathrm{v} / \mathrm{v})$ to assist solubilization of the compound. Followed by incubation, the cells were washed with phosphate-buffered saline and mounted on grease free glass slide and observed under a Leica TCS SP8, a confocal laser scanning fluorescence microscope.

4.3.1.3. MTT Assay for the Assessment Cytotoxicity. The cytotoxicity of the compound DBTC against human breast adenocarcinoma cells MDA was assessed by exploring the colorimetric and quantitative MTT [3-(4,5-dimethylthiazol-2yl)-2,5-diphenyltetrazolium bromide] reduction assay. After complete adherence cells were treated for 1 and $24 \mathrm{~h}$ separately in preoptimized doses (100 and $200 \mu \mathrm{g} / \mathrm{mL}$ ) of DBTC with or without cyanide ion solution $(20 \mu \mathrm{L})$. After completion of treatment, the cells were washed with complete media and resuspended in MTT solution $(0.5 \mathrm{mg} / 1 \mathrm{~mL})$ and incubated at $37{ }^{\circ} \mathrm{C}$ for $4 \mathrm{~h}$ at dark. Dark violet formazan crystals were formed as a result of reaction between MTT and mitochondrial succinate dehydrogenase enzyme (present only in living cells). The resulting crystals were dissolved in DMSO. Cellular viability was determined by quantifying the intensity of formazan crystal using a microplate reader (Bio-Rad).

4.4. Characterization of DBTC. 4.4.1. DBTC $\left(\mathrm{C}_{16} \mathrm{H}_{9} \mathrm{NO}_{2} \mathrm{~S}\right)$. Calcd C, 68.80; $\mathrm{H}, 3.25, \mathrm{~N}$ 5.01, O 11.46; Anal. Found: C, 68.47; H, 3.08; N, 4.81. mp $224 \pm 2{ }^{\circ} \mathrm{C}$. ESIMS: $\left[\right.$ DBTC $\left.+\mathrm{H}^{+}\right] \mathrm{m} / \mathrm{z}: 280.00$ (observed) [(calcd: $\mathrm{m} / \mathrm{z}$ : 279.03; where DBTC = molecular weight of organic moiety]; ${ }^{1} \mathrm{H}$ NMR (DMSO- $d_{6}, 400 \mathrm{MHz}, \delta \mathrm{ppm}$ ): $7.491-7.453(\mathrm{t}, 1 \mathrm{H})$, $7.590-7.552(\mathrm{t}, 1 \mathrm{H}), 7.669-7.631(\mathrm{t}, 1 \mathrm{H}), 7.861-7.840(\mathrm{~d}$, $1 \mathrm{H}), 7.965-7.926(\mathrm{t}, 1 \mathrm{H}), 8.072-8.051(\mathrm{~d}, 1 \mathrm{H}), 8.210-8.191$ (d, $1 \mathrm{H}), 8.289-8.269(\mathrm{~d}, 1 \mathrm{H})$ and $9.542(\mathrm{~s}, 1 \mathrm{H}) ;{ }^{13} \mathrm{C}$ NMR $\left(400 \mathrm{~Hz}\right.$ DMSO- $\left.d_{6}\right): \delta 180.38,155.69,143.30,141.56,136.81$, $134.62,132.33,132.30,125.99,123.51,122.56,121.86,117.99$, $114.83,104.92$ and 100.01 ; IR data $\nu_{\mathrm{C}-\mathrm{S}}: 750.06, \nu_{\mathrm{C}=\mathrm{N}}$ : 1588.80, $\nu_{\mathrm{C}=\mathrm{O}}: 1652.77$.

4.5. Characterization of DBTC-CN Complex. 4.5.1. DBTC-CN $\left(\mathrm{C}_{34} \mathrm{H}_{18} \mathrm{~N}_{4} \mathrm{O}_{4} \mathrm{~S}_{2}\right)$. Calcd C, 66.87; H, 2.97; N, 9.17; O, 10.48; Anal. Found: C, 66.56; H, 3.21; N, 9.41. ESI-MS: [DBTC-CN] m/z: found 307.0522 and 611.0818 [calcd for $[\mathrm{M}+\mathrm{H}]^{+} 307.0536$, where $\mathrm{M}$ formulated as $\mathrm{C}_{17} \mathrm{H}_{10} \mathrm{~N}_{2} \mathrm{O}_{2} \mathrm{~S}$ and $[\mathrm{P}+\mathrm{H}]^{+}$611.0842, where $\mathrm{P}$ formulated as $\mathrm{C}_{34} \mathrm{H}_{18} \mathrm{~N}_{4} \mathrm{O}_{4} \mathrm{~S}_{2}$ ]; ${ }^{1} \mathrm{H}$ NMR (DMSO- $d_{6}, 400 \mathrm{MHz}, \delta \mathrm{ppm}$ ): $7.068-7.086$ (d, 2H), 7.140-7.198 (m, 4H), 7.329-7.365 (d, $2 \mathrm{H}), 7.404-7.422$ (d, 2H), 7.623-7.643 (d, 2H), 7.832$7.889(\mathrm{~m}, 4 \mathrm{H})$ and $8.461(\mathrm{~s}, 2 \mathrm{H}) ;{ }^{13} \mathrm{C}$ NMR $(400 \mathrm{~Hz}$ DMSO$\left.\left.d_{6}\right)\right): \delta 167.85,165.24,141.87,133.97,133.07,127.21,125.80$, 
125.63, 125.34, 124.62, 122.77, 121.91, 121.63, 121.25, 118.64, 118.41 and 117.97; IR data: $\nu_{\mathrm{S}-\mathrm{S}}: 668.32, \nu_{\mathrm{C}-\mathrm{S}}: 753.62, \nu_{\mathrm{C}=\mathrm{N}}$ : $1531.94, \nu_{\mathrm{C}=\mathrm{O}}: 1595.91, \nu_{\mathrm{CN}}: 2201.86$.

\section{ASSOCIATED CONTENT}

\section{S Supporting Information}

The Supporting Information is available free of charge on the ACS Publications website at DOI: 10.1021/acsomega.8b01035.

Mass spectrum of DBTC; ${ }^{1} \mathrm{H}$ NMR spectrum of DBTC and DBTC-CN compound in DMSO- $d_{6} ;{ }^{13} \mathrm{C}$ NMR spectrum of DBTC and DBTC-CN compound in DMSO- $d_{6}$; IR spectrum of DBTC; ESI-MS spectra of the DBTC-CN compound; IR spectra of the DBTC$\mathrm{CN}$ compound; fluorescence spectra for $\mathrm{pH}$ study of DBTC; time-dependent fluorescence study of DBTC; Job's plot of DBTC showing maxima at 1:1; anion selectivity of DBTC; change of relative fluorescence intensity profile of organic moiety; some HOMO and LUMO's of DBTC and DBTC-CN compound; and cytotoxic effect of DBTC (PDF)

Crystallographic data for DBTC (CIF)

Crystallographic data for DBTC-OCH 3 (1) (CIF)

\section{AUTHOR INFORMATION}

\section{Corresponding Author}

*E-mail: pabitracc@yahoo.com. Phone: +91-342-2558554 ext. 424. Fax: +91-342-2530452.

\section{ORCID $\odot$}

Koushik Dhara: 0000-0001-9388-9600

Pabitra Chattopadhyay: 0000-0002-5923-7462

\section{Notes}

The authors declare no competing financial interest.

\section{ACKNOWLEDGMENTS}

The authors gratefully acknowledge to Department of Science and Technology, Goverment of West Bengal (DST, GoWB, vide project no. 698 (Sanc.)/ST/P/S \& T/15-G/2015) for financial assistance. S.L. wishes to thank UGC, New Delhi, India, for offering him the SRF fellowship. The authors are thankful to USIC, The University of Burdwan for the singlecrystal X-ray diffractometer facility under PURSE program. The authors are highly grateful to DST-FIST program of Department of Zoology, Visva Bharati, India, for carrying out confocal microscopy.

\section{REFERENCES}

(1) Cho, D.-G.; Sessler, J. L. Modern reaction-based indicator systems. Chem. Soc. Rev. 2009, 38, 1647-1662.

(2) Duke, R. M.; Veale, E. B.; Pfeffer, F. M.; Kruger, P. E.; Gunnlaugsson, T. Colorimetric and fluorescent anion sensors: an overview of recent developments in the use of 1,8-naphthalimidebased chemosensors. Chem. Soc. Rev. 2010, 39, 3936-3653.

(3) Kim, H. N.; Guo, Z.; Zhu, W.; Yoon, J.; Tian, H. Recent progress on polymer-based fluorescent and colorimetric chemosensors. Chem. Soc. Rev. 2011, 40, 79-93.

(4) Wenzel, M.; Hiscock, J. R.; Gale, P. A. Anion receptor chemistry: highlights from 2010. Chem. Soc. Rev. 2012, 41, 480-520.

(5) Gale, P. A.; Busschaert, N.; Haynes, C. J. E.; Karagiannidis, L. E.; Kirby, I. L. Anion receptor chemistry: highlights from 2011 and 2012. Chem. Soc. Rev. 2014, 43, 205-241.

(6) Lohar, S.; Pal, S.; Sen, B.; Mukherjee, M.; Banerjee, S.; Chattopadhyay, P. Selective and Sensitive Turn-on Chemosensor for
Arsenite Ion at the ppb Level in Aqueous Media Applicable in Cell Staining. Anal. Chem. 2014, 86, 11357-11361.

(7) Lohar, S.; Maji, A.; Pal, S.; Mukhopadhyay, S. K.; Nag, D.; Demitri, N.; Chattopadhyay, P. Naphthalimide-Based Turn-On Fluorosensor for Aqueous Sulfide Ions for Staining in Living Cells. ChemistrySelect 2017, 2, 9977-9983.

(8) Kaushik, R.; Ghosh, A.; Singh, A.; Gupta, P.; Mittal, A.; Jose, D. A. Selective detection of cyanide in water and biological samples by an off-the-shelf compound. ACS Sens. 2016, 1, 1265-1271.

(9) Lee, K.-S.; Kim, H.-J.; Kim, G.-H.; Shin, I.; Hong, J.-I. Fluorescent chemodosimeter for selective detection of cyanide in water. Org. Lett. 2007, 10, 49-51.

(10) Holzbecher, M. D.; Moss, M. A.; Ellenberger, H. A. The cyanide content of laetrile preparations, apricot, peach and apple seeds. J. Toxicol. Clin. Toxicol. 1984, 22, 341-347.

(11) Dash, R. R.; Gaur, A.; Balomajumder, C. Cyanide in industrial wastewaters and its removal: A review on biotreatment. J. Hazard. Mater. 2009, 163, 1-11.

(12) Xu, Z.; Chen, X.; Kim, H. N.; Yoon, J. Sensors for the optical detection of cyanide ion. Chem. Soc. Rev. 2010, 39, 127-137.

(13) Liu, J.; Liu, Y.; Liu, Q.; Li, C.; Sun, L.; Li, F. Iridium(III) Complex-Coated Nanosystem for Ratiometric Upconversion Luminescence Bioimaging of Cyanide Anions. J. Am. Chem. Soc. 2011, 133, 15276-15279.

(14) Kim, D.; Na, S.-Y.; Kim, H.-J. A fluorescence turn-on probe for a catalytic amount of cyanides through the cyanide-mediated cinnamate-to-coumarin transformation. Sens. Actuators, B 2016, 226, 227-231.

(15) Shan, D.; Mousty, C.; Cosnier, S. Subnanomolar cyanide detection at polyphenol oxidase/clay biosensors. Anal. Chem. 2004, $76,178-183$.

(16) Sun, Y.; Wang, G.; Guo, W. Colorimetric detection of cyanide with N-nitrophenyl benzamide derivatives. Tetrahedron 2009, 65, 3480-3485.

(17) Koenig, R. Wildlife deaths are a grim wake-up call in eastern europe. Science 2000, 287, 1737-1738.

(18) Marsden, J.; House, I. The Chemistry of Gold Extraction; SME: Littleton, Colorado, USA, 2006.

(19) The Agency for Toxic Substances and Disease Registry. Toxicological Profile for Cyanide; US Department of Health and Human Services: Atlanta, GA, 2010; pp 221-228, http://www.atsdr. cdc.gov/toxprofiles/tp8-c8.pdf (accessed Jan 9, 2010).

(20) United States Environmental Protection Agency (EPA). Methods for Chemical Analysis of Water and Wastes; Environmental Monitoring and Support Laboratory: Cincinnati, OH, 1983, http:// www.epa.gov/ogwdw000/contaminants/basicinformation/cyanide. html (accessed Jan 9, 2010).

(21) World Health Organization. Guidelines for Drinking-Water Quality, 3rd ed., Geneva, 2008; pp 188, http://www.who.int/ watersanitationhealth/dwq/fulltext.pdf (accessed January 9, 2010).

(22) Australian and New Zealand Environmental and Conservation Council (ANZECC). Australian Water Quality Guidelines for Fresh and Marine Water; Agriculture and Resource Management Council of Australia and New Zealand, 2000; pp 3.4-5, http://www.mincos.gov. au/data/assets/pdffile/0019/316126/wqg-ch3.pdf (accessed Jan 9, 2010).

(23) Shan, D.; Mousty, C.; Cosnier, S. Subnanomolar cyanide detection at polyphenol oxidase/clay biosensors. Anal. Chem. 2004, 76, 178-183.

(24) Kaloo, M. A.; Sankar, J. Reusable and specific proton transfer signalling by inorganic cyanide in solution and solid phase $\dagger$. Chem. Commun. 2015, 51, 14528-14531.

(25) Bohrer, D.; do Nascimento, C. P.; Pomblum, S. G.; Seibert, E.; de Carvalho, L. M. Polarographic determination of cyanide as nickelcyano complex in blood plasma after selective extraction in a methylene blue impregnated polyethylene column. Fresenius' J. Anal. Chem. 1998, 361, 780-783. 
(26) Recalde-Ruiz, D. L.; Andrés-García, E.; Díaz-García, M. E. Fluorimetric flow injection and flow-through sensing systems for cyanide control in waste water. Analyst 2000, 125, 2100-2105.

(27) Dadfarnia, S.; Shabani, M. A. H.; Tamadon, F.; Rezaei, M. Indirect determination of free cyanide in water and industrial waste water by flow injection-atomic absorption spectrometry. Microchim. Acta 2007, 158, 159-163.

(28) Dhara, K.; Lohar, S.; Patra, A.; Roy, P.; Saha, S. K.; Sadhukhan, G. C.; Chattopadhyay, P. A New Lysosome-Targetable Turn-On Fluorogenic Probe for Carbon Monoxide Imaging in Living Cells. Anal. Chem. 2018, 90, 2933-2938.

(29) Lohar, S.; Pal, S.; Mukherjee, M.; Maji, A.; Demitri, N.; Chattopadhyay, P. A turn-on green channel $\mathrm{Zn}^{2+}$ sensor and the resulting zinc(II) complex as a red channel $\mathrm{HPO}_{4}{ }^{2-}$ ion sensor: a new approach. RSC Adv. 2017, 7, 25528.

(30) Ekmekci, Z.; Yilmaz, M. D.; Akkaya, E. U. A Monostyrylboradiazaindacene (BODIPY) Derivative as Colorimetric and Fluorescent Probe for Cyanide Ions. Org. Lett. 2008, 10, 461-464.

(31) Lin, Q.; Liu, X.; Wei, T.-B.; Zhang, Y.-M. Reaction-Based Ratiometric Chemosensor for Instant Detection of Cyanide in Water with High Selectivity and Sensitivity. Chem.-Asian J. 2013, 8, 30153021.

(32) Jo, J.; Olasz, A.; Chen, C.-H.; Lee, D. Interdigitated Hydrogen Bonds: Electrophile Activation for Covalent Capture and Fluorescence Turn-On Detection of Cyanide. J. Am. Chem. Soc. 2013, 135, 3620-3632.

(33) Yang, L.; Li, X.; Yang, J.; Qu, Y.; Hua, J. Colorimetric and ratiometric near-infrared fluorescent cyanide chemodosimeter based on phenazine derivatives. ACS Appl. Mater. Interfaces 2013, 5, 13171326.

(34) Lin, Y.-D.; Pen, Y.-S.; Su, W.; Liau, K.-L.; Wen, Y.-S.; Tu, C.H.; Sun, C.-H.; Chow, T. J. Reaction-Based Colorimetric and Ratiometric Fluorescence Sensor for Detection of Cyanide in Aqueous Media. Chem.-Asian J. 2012, 7, 2864-2871.

(35) Bhalla, V.; Pramanik, S.; Kumar, M. Cyanide modulated fluorescent supramolecular assembly of a hexaphenylbenzene derivative for detection of trinitrotoluene at the attogram level. Chem. Commun. 2013, 49, 895-897.

(36) Saha, S.; Ghosh, A.; Mahato, P.; Mishra, S.; Mishra, S. K.; Suresh, E.; Das, S.; Das, A. Specific Recognition and Sensing of CNin Sodium Cyanide Solution. Org. Lett. 2010, 12, 3406-3409.

(37) Wei, S. C.; Hsu, P.-H.; Lee, Y.-F.; Lin, Y.-W.; Huang, C.-C. Selective Detection of Iodide and Cyanide Anions Using GoldNanoparticle-Based Fluorescent Probes. ACS Appl. Mater. Interfaces 2012, 4, 2652-2658.

(38) Panja, A.; Ghosh, K. Pyridylazo Derivatives with Dicyanovinyl Appendage in Selective Sensing of $\mathrm{CN}^{-}$in Sol-Gel Medium. ChemistrySelect 2018, 3, 1809-1814.

(39) Lin, Q.; Mao, P.-P.; Fan, Y.-Q.; Liu, L.; Liu, J.; Zhang, Y.-M.; Yao, H.; Wei, T.-B. A novel supramolecular polymer gel based on naphthalimide functionalized-pillar[5]arene for the fluorescence detection of $\mathrm{Hg} 2+$ and $\mathrm{I}-$ and recyclable removal of $\mathrm{Hg} 2+$ via cation $-\pi$ interactions. Soft Matter 2017, 13, 7085.

(40) Chen, J.-F.; Lin, Q.; Zhang, Y.-M.; Yao, H.; Wei, T.-B. Pillararene-based fluorescent chemosensors: recent advances and perspectives. Chem. Commun. 2017, 53, 13296-13311.

(41) Zhang, Y.-M.; Zhu, W.; Qu, W.-J.; Zhong, K.-P.; Chen, X.-P.; Yao, H.; Wei, T.-B.; Lin, Q. Competition of cation $-\pi$ and exo-wall $\pi-\pi$ interactions: a novel approach to achieve ultrasensitive response. Chem. Commun. 2018, 54, 4549-4552.

(42) Lin, Q.; Lu, T.-T.; Zhu, X.; Wei, T.-B.; Li, H.; Zhang, Y.-M. Rationally introduce multi-competitive binding interactions in supramolecular gels: a simple and efficient approach to develop multi-analyte sensor arrayt. Chem. Sci. 2016, 7, 5341-5346.

(43) Lin, Q.; Zhong, K.-P.; Zhu, J.-H.; Ding, L.; Su, J.-X.; Yao, H.; Wei, T.-B.; Zhang, Y.-M. Iodine Controlled Pillar[5]arene-Based Multiresponsive Supramolecular Polymer for Fluorescence Detection of Cyanide, Mercury, and Cysteine. Macromolecules 2017, 50, 78637871.
(44) Lin, Q.; Fan, Y.-Q.; Mao, P.-P.; Liu, L.; Liu, J.; Zhang, Y.-M.; Yao, H.; Wei, T.-B. Pillar [5] arene-Based Supramolecular Organic Framework with Multi-Guest Detection and Recyclable Separation Properties. Chem.-Eur. J. 2018, 24, 777-783.

(45) Chung, S.-Y.; Nam, S.-W.; Lim, J.; Park, S.; Yoon, J. A highly selective cyanide sensing in water via fluorescence change and its application to in vivo imaging. Chem. Commun. 2009, 2866-2868.

(46) Lou, X.; Qiang, L.; Qin, J.; Li, Z. A new rhodamine-based colorimetric cyanide chemosensor: convenient detecting procedure and high sensitivity and selectivity. ACS Appl. Mater. Interfaces 2009, $1,2529-2535$.

(47) Bhalla, V.; Singh, H.; Kumar, M. Triphenylene based copper ensemble for the detection of cyanide ions. Dalton Trans. 2012, 41, 11413-11418.

(48) Li, J.-J.; Wei, W.; Qi, X.-L.; Xu, X.; Liu, Y.-C.; Lin, Q.-H.; Dong, W. Rational design, synthesis of reaction-based dual-channel cyanide sensor in aqueous solution. Spectrochim. Acta, Part A 2016, 152, 288293.

(49) Lin, Q.; Chen, P.; Fu, Y.-P.; Zhang, Y.-M.; Shi, B.-B.; Zhang, P.; Wei, T.-B. A green synthesis of a simple chemosensor that could instantly detect cyanide with high selectivity in aqueous solution. Chin. Chem. Lett. 2013, 24, 699-702.

(50) Jeong, J. W.; Angupillai, S.; Kim, I. J.; Jeong, J.; Kim, H.-S.; So, H.-S.; Son, Y.-A. Michael addition-based colorimetric and fluorescence chemodosimeters for the nanomolar-level tracking of cyanide ions in aqueous-organic media. Sens. Actuators, B 2016, 237, 341349.

(51) Cheng, X.; Tang, R.; Jia, H.; Feng, J.; Qin, J.; Li, Z. New Fluorescent and Colorimetric Probe for Cyanide: Direct Reactivity, High Selectivity, and Bioimaging Application. ACS Appl. Mater. Interfaces 2012, 4, 4387-4392.

(52) Lin, W.-C.; Hu, J.-W.; Chen, K.-Y. A ratiometric chemodosimeter for highly selective naked-eye and fluorogenic detection of cyanide. Anal. Chim. Acta 2015, 893, 91-100.

(53) Wang, L.; Li, L.; Cao, D. A BODIPY-based dye with red fluorescence in solid state and used as a fluorescent and colorimetric probe for highly selective detection of cyanide. Sens. Actuators, $B$ 2017, 239, 1307-1317.

(54) El-Shishtawy, R. M.; Al-Zahrani, F. A. M.; Al-amshany, Z. M.; Asiri, A. M. Synthesis of a new fluorescent cyanide chemosensor based on phenothiazine derivative. Sens. Actuators, B 2017, 240, 288-296.

(55) Yang, L.; Li, X.; Yang, J.; Qu, Y.; Hua, J. Colorimetric and ratiometric near-infrared fluorescent cyanide chemodosimeter based on phenazine derivatives. ACS Appl. Mater. Interfaces 2013, 5, 13171326.

(56) Mahapatra, A. K.; Maiti, K.; Maji, R.; Manna, S. K.; Mondal, S.; Ali, S. S.; Manna, S. Ratiometric fluorescent and chromogenic chemodosimeter for cyanide detection in water and its application in bioimaging. RSC Adv. 2015, 5, 24274-24280.

(57) Yang, Y.; Zhao, Q.; Feng, W.; Li, F. Luminescent Chemodosimeters for Bioimaging. Chem. Rev. 2013, 113, 192-270.

(58) Bruker. SMART, SAINT; Software Reference Manual Bruker AXSInc: Madison, Wisconsin, USA, 2000.

(59) Sheldrick, G. M. Shelxs97 and Shelxl97 Programs for Crystallography; University of Göttingen: Germany, 1997.

(60) Farrugia, L. J. J. Appl. Crystallogr. 1999, 32, 837-838.

(61) Sheldrick, G. M. A short history of SHELX. Acta Crystallogr., Sect. A: Found. Crystallogr. 2008, 64, 112-122.

(62) Cossi, M.; Rega, N.; Scalmani, G.; Barone, V. Energies, structures, and electronic properties of molecules in solution with the C-PCM solvation model. J. Comput. Chem. 2003, 24, 669-681.

(63) Cossi, M.; Barone, V. Time-dependent density functional theory for molecules in liquid solutions. J. Chem. Phys. 2001, 115, $4708-4717$.

(64) Casida, M. E.; Jamorski, C.; Casida, K. C.; Salahub, D. R. Molecular excitation energies to high-lying bound states from timedependent density-functional response theory: Characterization and correction of the time-depen... J. Chem. Phys. 1998, 108, 4439. 
(65) O’Boyle, N. M.; Tenderholt, A. L.; Langner, K. M. cclib: a library for package-independent computational chemistry algorithms. J. Comput. Chem. 2008, 29, 839-845.

(66) Benesi, H. A.; Hildebrand, J. H. A spectrophotometric investigation of the interaction of iodine with aromatic hydrocarbons. J. Am. Chem. Soc. 1949, 71, 2703-2707.

(67) Pal, S.; Lohar, S.; Mukherjee, M.; Chattopadhyay, P.; Dhara, K. A fluorescent probe for the selective detection of creatinine in aqueous buffer applicable to human blood serum. Chem. Commun. 2016, 52, 13706-13709.

(68) Mukherjee, T.; Pessoa, J. C.; Kumar, A.; Sarkar, A. R. Oxidovanadium(IV) Schiff Base Complex Derived from Vitamin B6: Synthesis, Characterization, and Insulin Enhancing Properties. Inorg. Chem. 2011, 50, 4349-4361.

(69) Roy, P.; Saha, S. K.; Gayen, P.; Chowdhury, P.; Babu, S. P. S. Exploration of antifilarial activity of gold nanoparticle against human and bovine filarial parasites: A nanomedicinal mechanistic approach. Colloids Surf., B 2018, 161, 236-243. 